\title{
Conservative Treatment of Lung Perforation Secondary to Retained Catheter in an Extremely Low-Birth-Weight Premature Infant
}

\author{
Mehmet Surhan Arda ${ }^{1}$ Miller C. Hamrick ${ }^{2}$ Timothy D. Kane ${ }^{2}$ \\ ${ }^{1}$ Department of Pediatric Surgery, Eskisehir Osmangazi University \\ Medical School, Eskisehir, Turkey \\ 2 Department of Pediatric Surgery, Children's National Medical Center, \\ Washington, District of Columbia, United States \\ Address for correspondence Mehmet Surhan Arda, MD, Department \\ of Pediatric Surgery, Eskisehir Osmangazi University Medical School, \\ Meselik Campus, Eskisehir 26480, Turkey \\ (e-mail: msarda@ogu.edu.tr; ardasur@gmail.com).
}

Eur J Pediatr Surg Rep 2015;3:68-70.
Abstract
Keywords
- lung perforation
- tension pneumothorax
- treatment
- premature

Airway injury may occur during the use of any instrumentation in premature infants. A surgical approach for the treatment of lung perforation in extremely low-birth-weight infants has been recommended in the past. Here, we present a case of lung perforation in an ex-28-week, 730-g premature infant, who sustained lung perforation, secondary to an 8-Fr suction catheter used to administer surfactant, in which the broken catheter was retained in the airway. Following removal of catheter by endoscopy, tension pneumothorax had occurred. Attempts were made to treat the patient with single chest tube, unfortunately as it was not efficacious, the second one was placed on the ipsilateral side of hemithorax and the patient recovered without further surgery.

\section{New Insights and the Importance for the Pediatric Surgeon}

Surfactant is one of the frequent applied medicines in neonatal intensive care units. Besides its advantages, pneumothorax is also a frequent complication following its application. Lung perforation due to closed suction tube has been published and especially in neonates surgical treatment has been recommended. However treatment with chest tube furthermore with double chest tube has not been reported in an extremely low birth weight neonate. We suggest that conservative treatment should be the first choice before surgery.

\section{Introduction}

Tracheobronchial injury is a life-threatening problem that should be managed immediately in premature infants. Injuries may occur following any intervention to the tracheobronchial system. For proximal injuries, endotracheal intubation is both a cause and the treatment in most cases. However, for distal injuries, especially in premature newborns, usually surgical repair is recommended. ${ }^{1,2}$ Here we present a case of lung perforation with tension pneumothorax, in an ex-28-week 730-g premature infant, secondary to a broken and retained suction catheter tube. The infant was treated with two ipsilateral chest tubes without additional intervention.

received

February 22, 2015 accepted after revision March 30, 2015

published online

June 26, 2015

\section{Case}

A 730-g, ex-28-week gestational age female infant, who was a twin, was born via cesarean section with the Apgar scores 4/7. The mother was a 20 -year-old $G_{1} P_{0}$, who presented with placental abruption following blunt abdominal trauma during a basketball game. After delivery, the infant was transferred to a neonatal intensive care unit (NICU), and unfortunately the twin sibling died at birth.

On the second day of life (DOL), the infant was referred to Children's National Medical Center after finding a foreign body (8-Fr suction catheter) in the right side of mediastinum on chest X-ray following surfactant administration ( - Fig. 1).

\footnotetext{
(c) 2016 Georg Thieme Verlag KG Stuttgart · New York
}

License terms

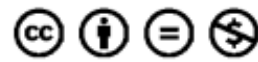




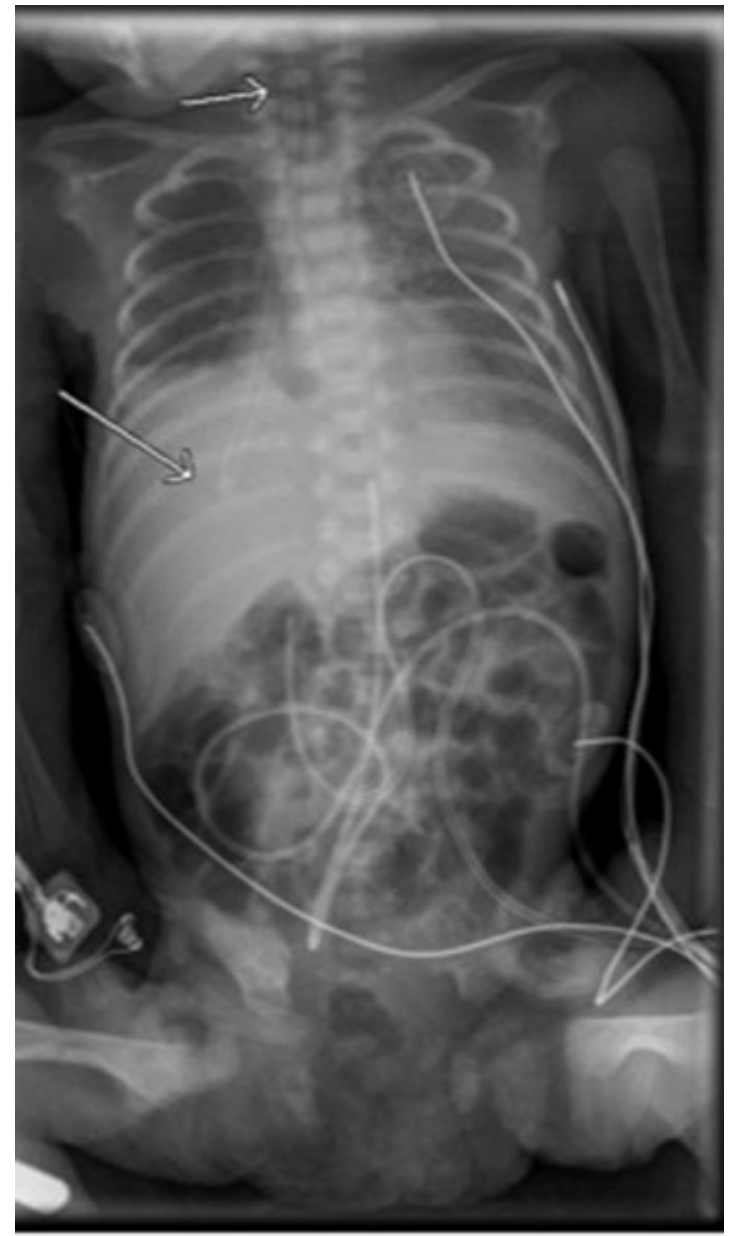

Fig. 1 Chest X-ray. Arrow on chest computed tomography indicates the proximal and distal tips of foreign body.

The infant was doing well upon admission and did not require mechanical ventilation. The vital signs were as follows: $\mathrm{O}_{2}$ saturation $\left(\mathrm{SpO}_{2}\right) 93$ to $100 \%$; heart rate 149 to 190 beats/ min; respirations 30 to 88 breaths/min; blood pressure systolic 52 to $73 \mathrm{~mm} \mathrm{Hg}$ and diastolic 29 to $47 \mathrm{~mm} \mathrm{Hg}$. However, a retained suction catheter was evident on imaging with the upper proximal end beginning at the level of vocal

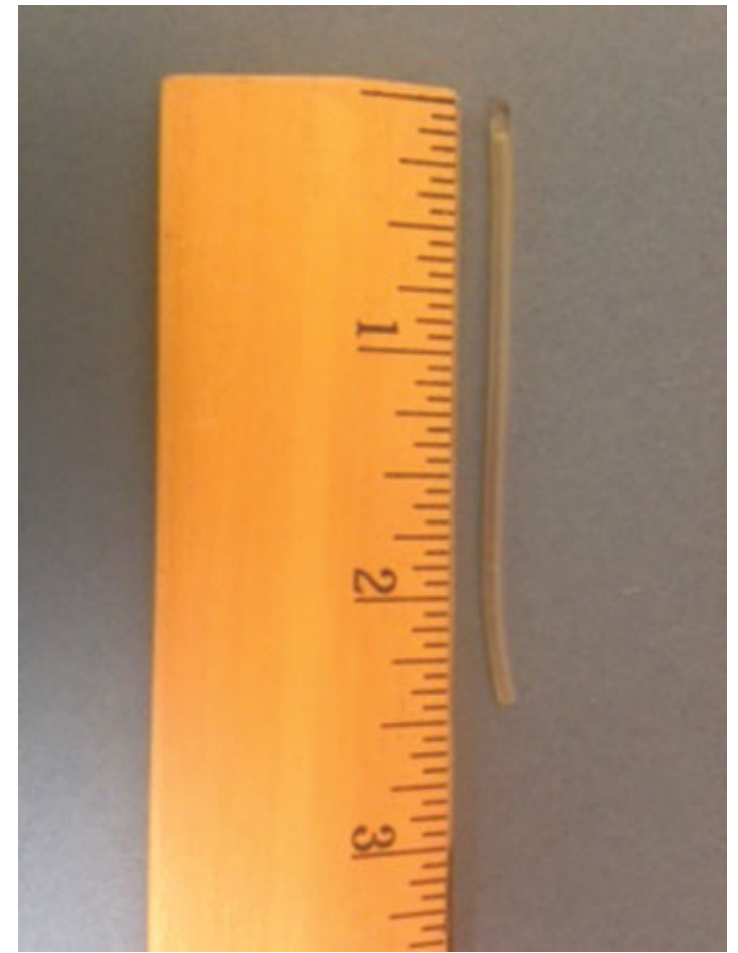

Fig. 3 Removed suction catheter.

cords and extending distally to the right hemidiaphragm. On computed tomography (CT) of the chest, atelectasis of right lower lobe without pneumothorax was demonstrated (-Fig. 2). The infant underwent general anesthesia and an approximately $6.50-\mathrm{cm}$ stiff suction cannula was removed with an optical grasping forceps via a $1.1-\mathrm{mm}$ bronchoscope (-Fig. 3). The infant decompensated immediately upon removal of the foreign body and a presumed right-sided tension pneumothorax was immediately treated with a single chest tube, and the infant was stabilized for transfer back to the NICU. A persistent air leak necessitated subsequent placement of a second chest tube, and thereafter the patient did well. One chest tube was removed on postoperative day 19 , and the second was removed 1 day later. The infant was

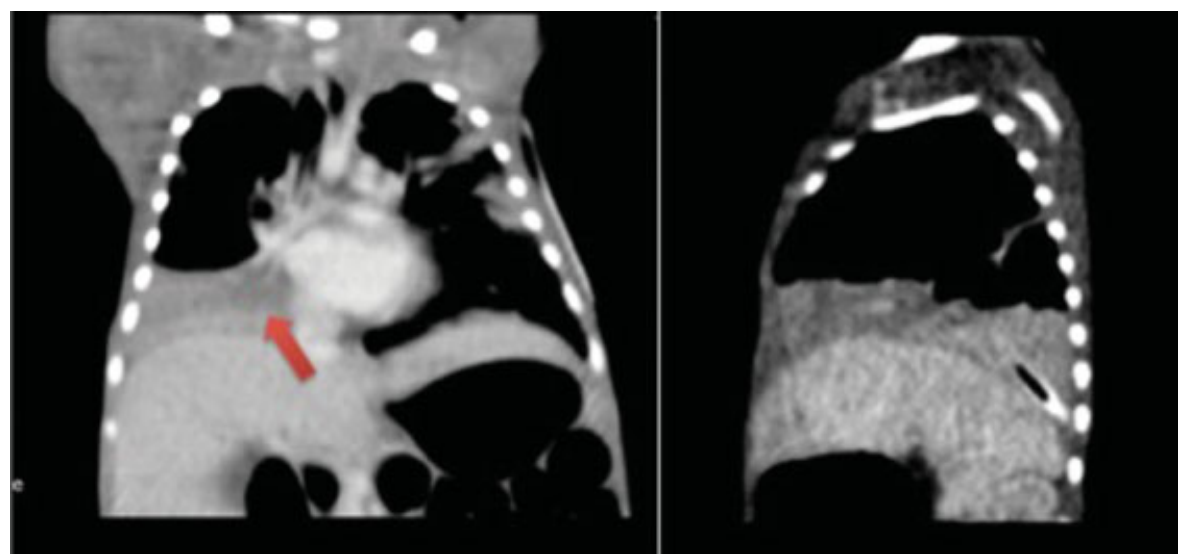

Fig. 2 Computed tomography of the chest (coronal and sagittal). Arrow on the chest X-ray indicates the foreign body at the hemithorax. 
extubated on the 30th postoperative day. During follow-up of 10 months, the infant did well and had no further problems related to pneumothorax.

\section{Discussion}

The most common laryngotracheoesophageal injury is the perforation of posterior pharynx due to attempts at airway intubation, nasogastric tube placement, or oral suctioning. ${ }^{3}$ Airway injury due to several kinds of instrumentation such as closed-tube endotracheal suction or bronchoscopy just at the time of intubation has been published previously. ${ }^{1-3}$ However, retention of a broken suction tube in a premature infant following surfactant administration has not been reported in the literature. Retention of a suction catheter in a 3,500-g infant with pneumothorax was described by Garcia-Aparicio et al although no perforation was found when the catheter was removed. 4

In extremely low-birth-weight infants, it is difficult to diagnose and manage bronchial injuries. If the injury is within the proximal trachea, endotracheal intubation is the primary treatment. However, premature infants with injury to the distal areas of the tracheobronchial system are difficult to manage, and a surgical approach is recommended and in recent reports. ${ }^{5}$ There has been only one report of one extremely low-birth-weight infant with bronchial perforation and attempted management by chest tube, alone which failed. ${ }^{2}$ For surgical treatment via thoracotomy, the options included primary suture repair, tissue-glue application, or lobectomy performed via thoracotomy. ${ }^{1,2,5}$ Therefore, in consideration of the morbidity associated with thoracotomy in a premature infant, we initially opted to perform chest tube placement followed by a second chest tube when the air leak persisted. If tube thoracostomy fails, thoracotomy remains an option.

Pneumothorax is a well-known complication following surfactant application. ${ }^{6}$ However, tracheobronchial perforation following surfactant application due to a broken suction tube without initial impairment of patient's vital signs, in an extremely low birth weight infant, has not been previously described in the literature. Chest tube thoracostomy, and if necessary more than one, is a good alternative treatment before invasive surgery, even in extremely premature infants.

\section{References}

1 McCann U, Kane K, Nicolette L, Ratner M, Baesl T. Primary repair of a neonatal bronchial intubation injury. J Pediatr Surg 2006;41(3): 570-572

2 Thakur A, Buchmiller T, Atkinson J. Bronchial perforation after closed-tube endotracheal suction. J Pediatr Surg 2000;35(9): 1353-1355

3 Dastidar A. Pneumomediastinum, pneumoperitoneum and pneumothorax following iatrogenic perforation of bronchus: successful conservative management of a potentially serious complication. J Pediatr Surg 2013;48(2):456-458

4 Garcia-Aparicio L, Castañón M, Tarrado X, Rodríguez L, Iriondo M, Morales L. Bronchial complication of a closed-tube endotracheal suction catheter. J Pediatr Surg 2002;37(10):1483-1484

5 Gien J, Ing RJ, Twite MD, Campbell D, Mitchell M, Kinsella JP. Successful surgical management of airway perforation in preterm infants. J Pediatr Surg Case Rep 2014;2(2):47-51

6 Duong HH, Mirea L, Shah PS, Yang J, Lee SK, Sankaran K. Pneumothorax in neonates: trends, predictors and outcomes. J Neonatal Perinatal Med 2014;7(1):29-38 